Sharif University of Technology
Scientia Iranica
SCIENTIA $\quad \begin{gathered}\text { Transactions D: Computer Science \& Engineering and Electrical Engineering } \\ \text { whw.scientiairanica.com }\end{gathered}$

\title{
Integrated system for the use of solar energy in animal farm
}

\author{
R. Omarov a , S. Abdygaliyeva ${ }^{b}$, D. Omar ${ }^{a}$ and M. Kunelbayev ${ }^{c, *}$ \\ a. Department of Electrification of Agriculture, Kazakh Scientific Research Institute of Mechanization and Electrification of \\ Agriculture, Almaty, Republic of Kazakhstan. \\ b. Faculty of Geography and Environmental Sciences, Al Farabi Kazakh National University, 050040, Almaty, Republic of \\ Kazakhstan. \\ c. Faculty of Physical-Mathematical, Kazakh State Women's Teacher Training University, Almaty, Republic of Kazakhstan.
}

Received 11 November 2015; received in revised form 4 July 2016; accepted 29 August 2016

\author{
KEYWORDS \\ Integrated technology; \\ Heat pump; \\ Compressor; \\ Condenser; \\ Evaporator; \\ Microprocessor \\ control; \\ Heating and cooling.
}

\begin{abstract}
The advent of unique technologies of the developing Solar Energy (SE), actual energy, faces economic and environmental problems. The main obstacle to the widespread use of SE is the low value of the average annual efficiency of known solar installations. In a sharply continental climate, they are exploited only in the warm season, about 6-7 months. Known combined systems, where additional conventional water heaters duplicate the operation of solar units, require additional costs for energy carriers. These disadvantages are not offered by the integrated system of SE use. In the article, the system was studied using the example of a cattle-breeding farm. The new system performs these functions; it recycles heat, organizes their movement and accumulation, and smooths out the uneven SE. The main components of the system are: Solar Power Plant (SPP), milk cooler, climate unit, Heat Pump (HP), the battery heat, automatic control system, and device heating and hot water. The main goal, i.e. lower cost of the energy produced and the elimination of the uneven SE, compared to the known SPP, is achieved through the flow of energy from the sources mentioned above.
\end{abstract}

(C) 2017 Sharif University of Technology. All rights reserved.

\section{Introduction}

The development of civilization in the 21 st century will inevitably face $3 \mathrm{E}$-trilemma, and intensification of economic development (E: Economy) requires an increase in energy consumption (E: Energy), which leads to global environmental pollution (E: Environment) and, accordingly, the end of civilization [1]. Out of the vicious circle, $3 \mathrm{E}$ : perspective is associated with the use of alternative technologies for the production of ther-

\footnotetext{
*. Corresponding author.

E-mail addresses: omarov-rashit@mail.ru (R. Omarov); slushash_abd@mail.ru (S. Abdygaliyeva); murat7508@yandex.ru (M. Kunelbayev)
}

doi: $10.24200 /$ sci. 2017.4358 mal energy and the widespread use of environmentallyfriendly Renewable Energy (RE). Renewable energy as a separate direction is especially considerable in rapidly developing countries with warm climates: the United States, Turkey, Italy, France, Spain, and others [2]. In countries with sharp continental climate, due to the short period of operation of Solar Power Plant (SPP), which does not exceed 6 months, they cannot practically compete with the traditional generators of thermal energy.

The thermal energy is particularly important in agriculture. Health, animal productivity, and product quality are directly dependent on the conditions such as the state of air quality of livestock premises. Therefore, processes, particularly heating, hot water, climate, storing perishable (meat, milk, meat, and dairy) products are associated with the consumption of a large 
amount of heat energy. Production facilities, including geographically distributed farm and the supply of power lines for them, are not economically justified. The use of traditional energy sources is not promising; it is not effective in terms of ecology and economy. At the same time, the sources are included in the system complementing each other and smoothing the unevenness of individual RE. The main components of such systems are RE, which belongs to the lowpotential power source, Heat Pump (HP), and heating the object [3-6].

\section{State of the problem}

The integrated system is implemented on the circuit of Dimplex. SPP is connected to the system through HP. If solar energy is insufficient or greater amount of heat is required, in conjunction with the HP, SC can provide heat absorption from ambient air [7-8]. It is known to use a combination of SC and HP for drying processes [9].

Research on the optimization of the parameters of the "ground heat exchanger-heat pump" has been conducted by scientists in France (Toulouse) and the USA (Denver) [10]. As the objective function is adopted with respect to cost, the calculation is carried out and the optimal size for the specific HP ground heat exchangers is determined. The research work objective of British scientists, Muhammad Waseem Ahmad et al. [11], i.e. to reduce the cost of heating and hot water at home, is achieved through the integration of HP, solar energy and electricity at night, which is cheaper than in the daytime, and storage of thermal energy in the heating tank. The system is controlled by an intelligent controller ON-OFF at several variables on the basis of predictive models (MPC). Scientists from Turkey (Eskisehir Osmangazi University) experimentally investigated the structure of the evaporator collector of solar energy, providing maximum efficiency when heating water in the heat pump system (DXSAHP) [12]. Canadian researchers from the University of Toronto studied the effectiveness of a hybrid device: heat pump-ground heat exchangers (GSHP) - solar thermal collectors [13]. Tests were conducted on an example of a house. The tool was used to simulate the system software TRNSYS, allowing for the simulation of the characteristics of a normal annual GSHP system as well as the proposed hybrid system GSH.

The system allows using three energy sources: solar energy, soil heat, and utilized heat of the air being removed. Simultaneously, the system provides air conditioning in the room, heating and hot water supply. There have been some research studies conducted on the integration of solar, geothermal energy, utilized heat refrigeration units, conditioned air, as well as the selection of working fluids for heat pump, including carbon dioxide, which refers to natural and environmentally-friendly refrigerants, since it does not deplete the ozone layer [15]. At the same time, the amount of absorbed solar energy was increased by $48 \%$ [16]. The closest analog integrated use of renewable energy is a waterring system, where all the low-potential and potential powers, regardless of their purpose at the moment (heating or cooling), are joined together with two-pipe low-temperature water network [17].

An example of the practical implementation of an integrated system of solar heating systems with multiple-renewable energy is the experience of heating the building of a new school of agriculture located in northern Italy. Renato [18] claimed that HP performance is enhanced through the use of several sources: air, ground heat, solar energy, and the heat returned from the school building ventilation. The energy balance shows that it has a high-potential heat ventilation air system with a maximum capacity of $146 \mathrm{~kW}$ space heating through the ventilation, which removes up to $122 \mathrm{~kW}$ of sensible heat; the integration of different sources not only increases the thermal efficiency of the overall system, but also optimizes the use of each source; additional savings can be obtained by proper selection of the room temperature. Figure 1 is a functional diagram of the HVAC (Heating, Ventilation, Air Conditioning), which shows the flow of fluid and energy flows. Heat pumps have been calculated to cover the base load, and the main boiler has been used to cover the peak load and provide redundancy in case of failure of the heat pump.

These integrated systems have the following disadvantages:

- In the known systems and devices, ineffective functionality is detected, in particular, in providing cooling and storing perishable products (milk and meat) with simultaneous utilization of the heat;

- Due to imperfections in the structure, it has a low heat-output VT;

- The system uses a large number of circulation pumps, leading to a reduction of reliability and additional operating costs.

\section{Description of the technology and systems}

The aim of our work is to increase functionality requirements, performance and reliability of the integrated system for the use of renewable energy. To achieve this goal, a solution is offered $[19,20]$.

The system is developed on the example of the dairy cattle farm, where capabilities of the system can be simulated most clearly (Figure 2).

The principle of the scheme shows 33 system components (Figure 2). The main ones are: HP; 


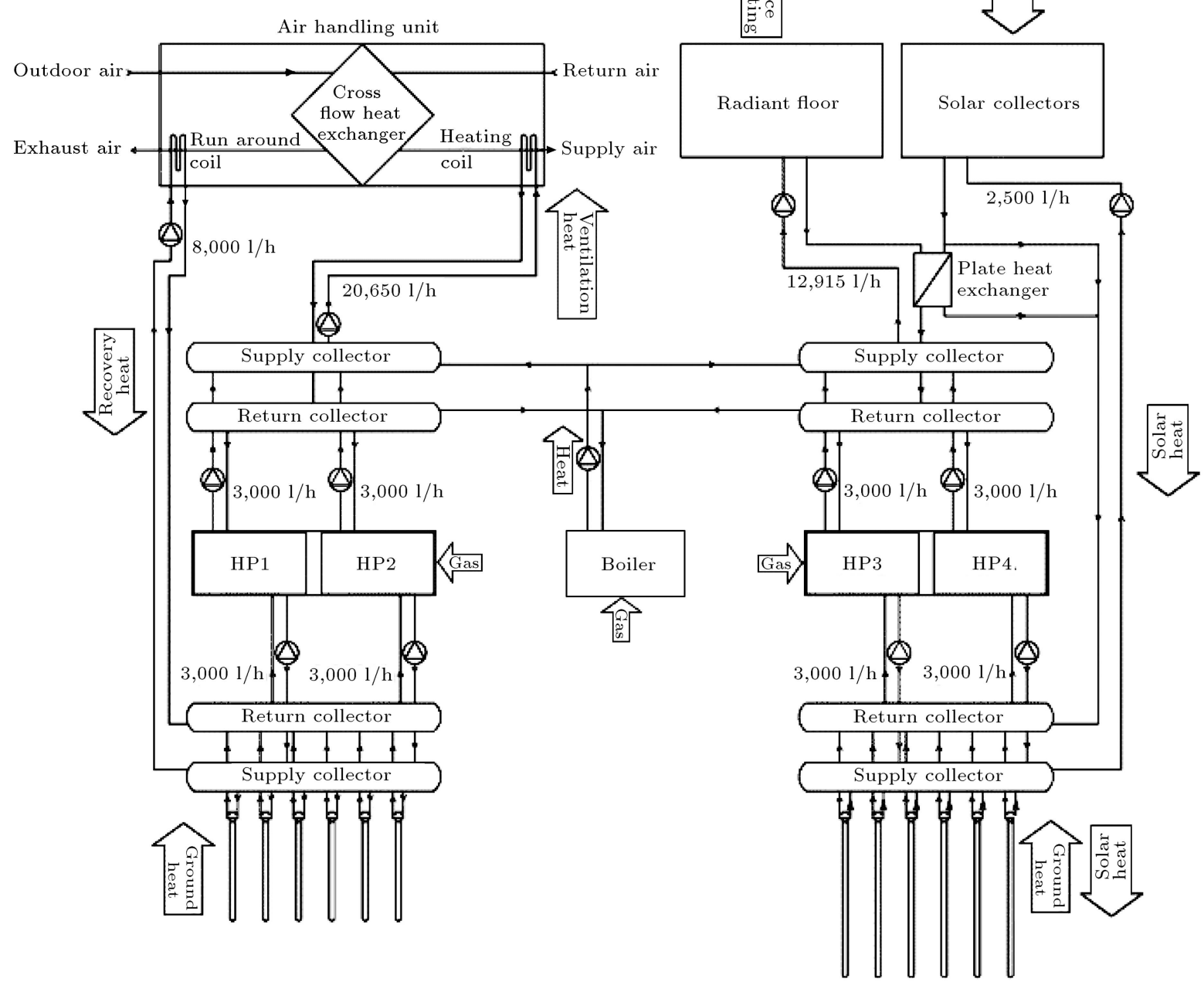

Figure 1. Functional diagram of the HVAC plant (shows the energy flows of gas, soil, sun, and heat recovery ventilation air).

ground heat exchangers; milk cooler; climate system; solar collector; storage tank; floor heating; circulation pumps; solenoid valves. Measuring equipment are: digital flowmeters water; hydrometer; pyranometer, temperature sensors; the microprocessor control; and start-protective electrical appliances. The operation is as follows.

When the system starts the operation in the microprocessor control unit 33, considering the priority of the task by means of circulation pump 9 , the heat pump is connected to evaporator 10 (Figure 2). From the milk cooler, heat absorbed by the evaporator is transferred to the refrigerant milk (freon), and then through the condenser HP compressor. After cooling is complete, the switching valves are connected to the microclimate evaporator system. The system absorbs excessive heat out of the room air through heat exchanger 4 , the transfer of its evaporator 1 . At the same time, disposing of excessive heat is done by air conditioning inside the building and the maintenance of its parameters at a given level. The novelty of the device is that it introduces additional functions: cooling and storing perishable products, maintaining a controlled indoor environment with the simultaneous utilization of waste heat, and increasing the heat capacity of HP. Thus, there is a lot of heat replenishment withdrawn from it during the winter and restoring its natural heat balance. The novelty of the device is that it introduces an additional function: cooling and storage of perishable products, maintaining a controlled indoor environment with simultaneous utilization of waste heat, increasing heat production of HP.

\section{Experimental studies}

Research studies, together with the HP SPP, are carried out on a laboratory bench simulation (Figure 3). The HP compressor capacity was $0,7 \mathrm{~kW}$. Instead, SPP used its model, Electric Water Heater $(\mathrm{EWH})$, where the required power is set using electric 

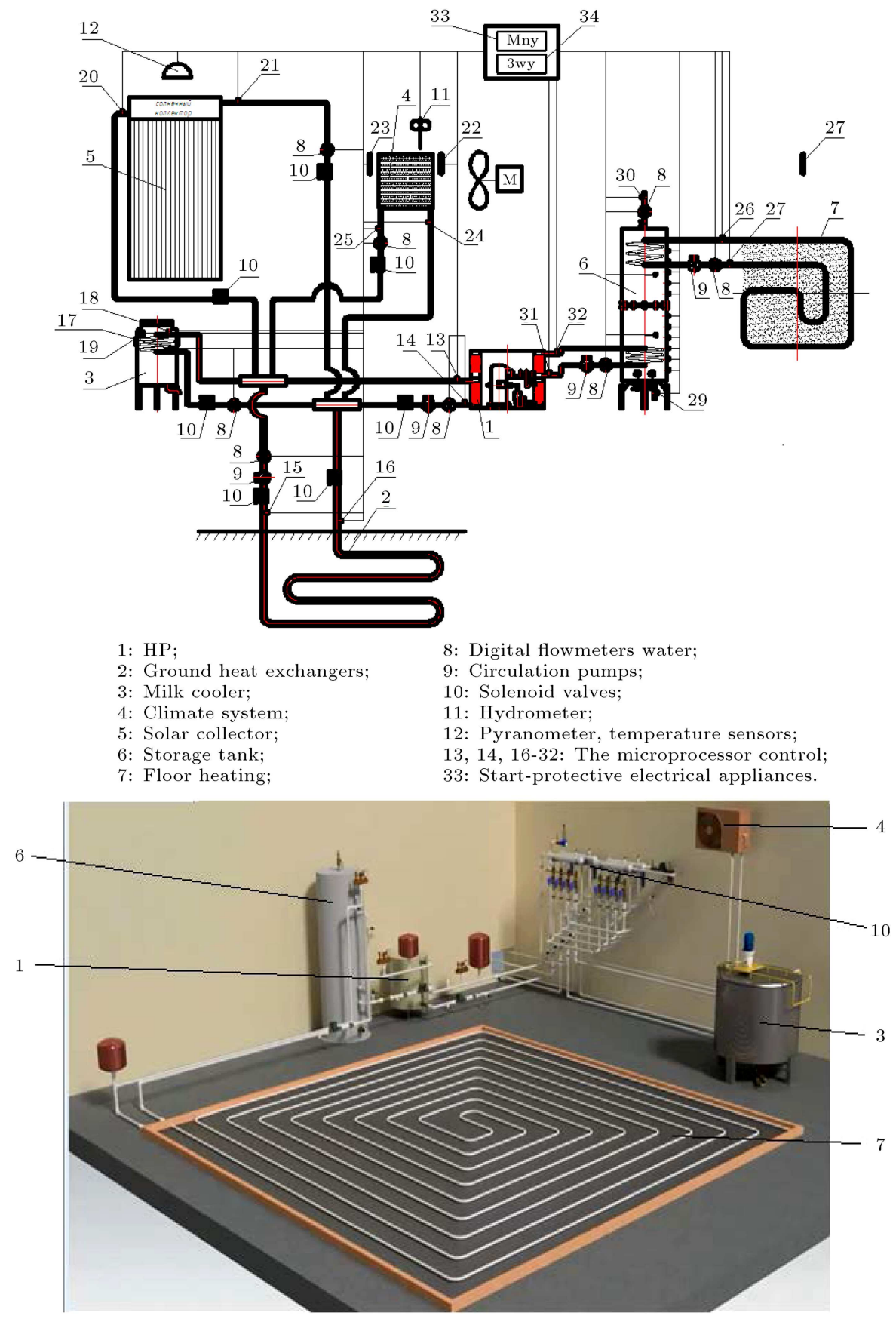

Figure 2. Schematic general view of the device for the integrated use of renewable energy.

autotransformer (EAT). The SPP was modeled with the power: $\mathrm{PSPP}=500,1000,1500,2000,3000$, and $4000 \mathrm{~W}$. The SPP performance in its joint operation with HP was carried out on a laboratory installation (Figure 4). The installation uses the electric water heater $(\mathrm{EWH})$ instead of the SPP. EWH is connected to the evaporator HP, the condenser HP is connected to the heater. During operation, the HP evaporator absorbs the heat produced by the EWH. Heat generated by the condenser HP is consumed by the heating device. The EWH power is controlled by an electric autotransformer (EAT). The system characteristics are studied at the following EWH powers: 500, 1000, 1500, 2000, 3000 and $4000 \mathrm{~W}$. The duration of the experiments at each stage was 90 minutes. In the course of the experiments, the following are measured: the temperature at the output from EWH $(t 2)$, at the output $(t 3)$ and input $(t 4)$ into the capacitor HP. Based on the results of the measurements, we plotted the dynamics of the temperatures of the heat carriers in time $t=f(\tau)$ and the thermal power of the developed HP. 


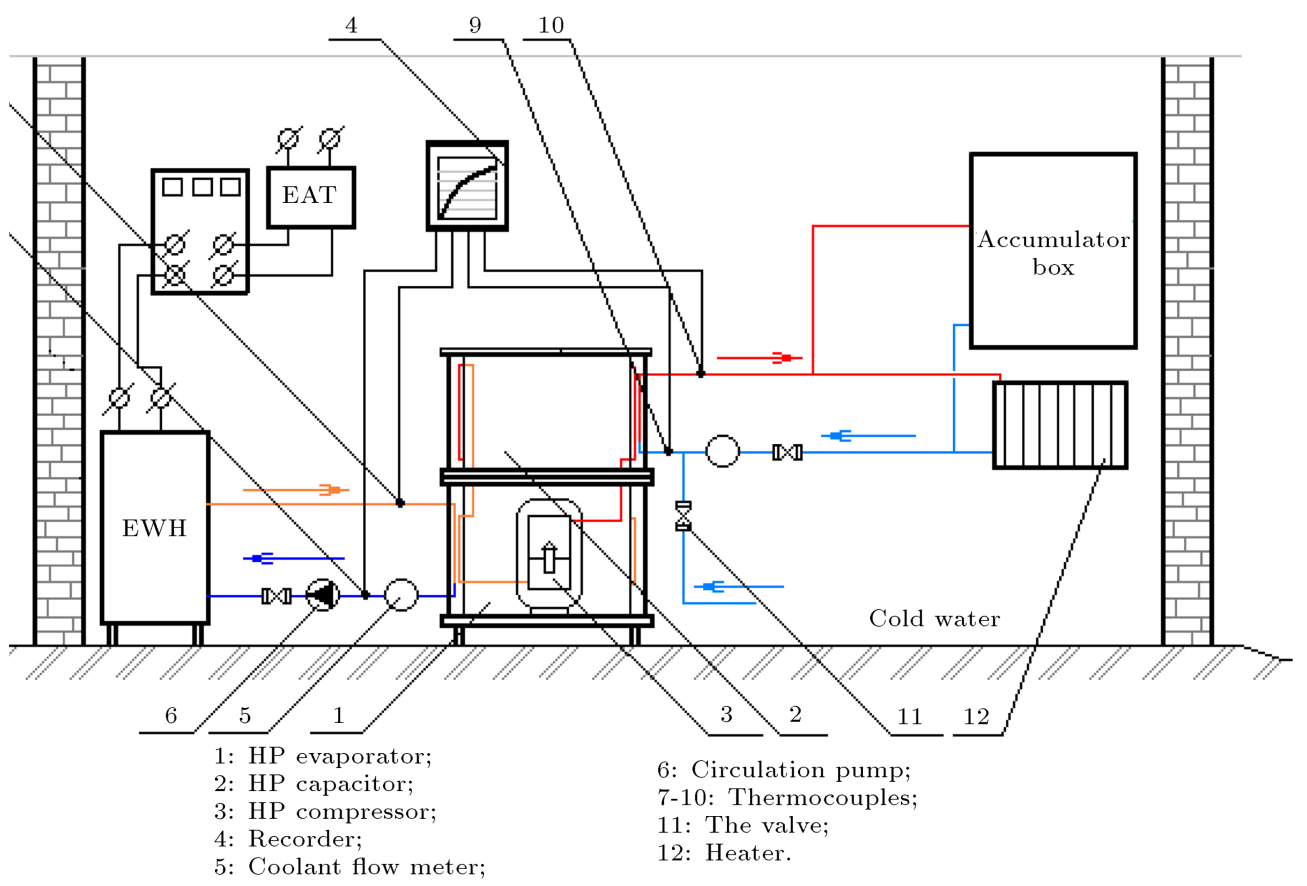

Figure 3. Scheme of the laboratory stands for research work together with the HP SPP.

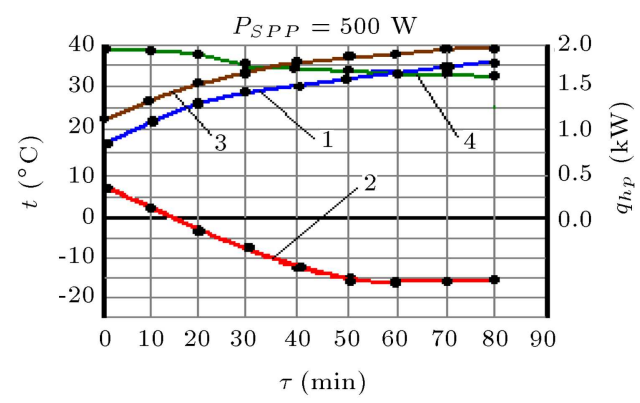

(a)

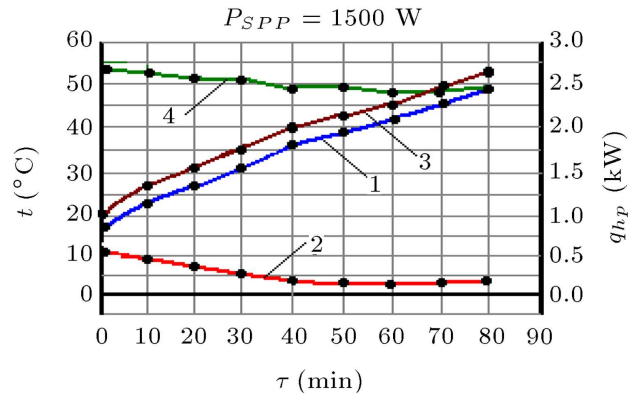

(c)

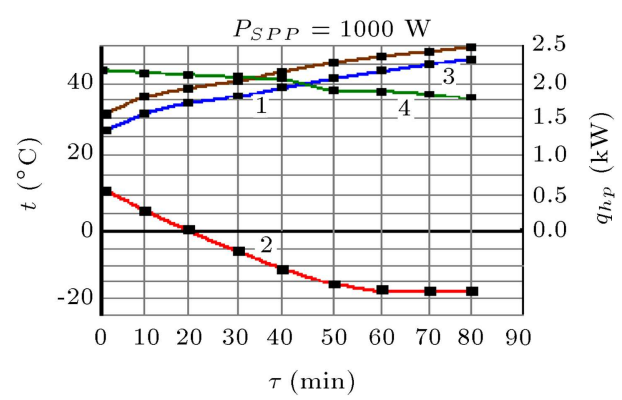

(b)

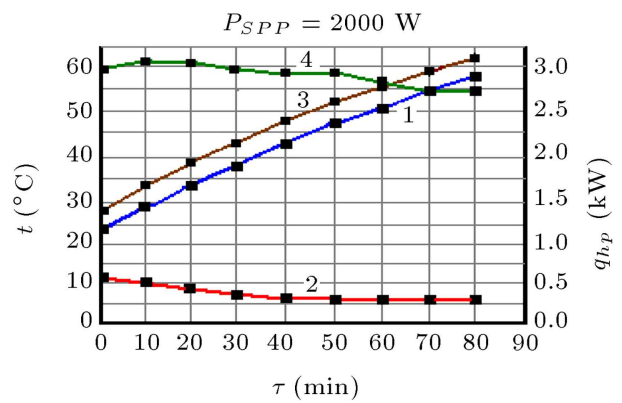

(d)

Figure 4. Graphs of the dynamics of the coolant temperatures at the inlet and outlet of the heating devices $(t 3, t 4)$, at the output of the SPP $(t 2)$ and the HP thermal power at various SPP capacities.

\section{Analysis of the results of experimental studies}

The measurement results are shown in Figure 4. Regarding the power SPP (i.e., power EWH), RSPP = $500 \mathrm{~W}$ on the output received $q_{h p}=1.95 \mathrm{~kW}$. The results of the measurements are shown in the graphs (Figure 5). With an EWH power of $500 \mathrm{~W}$, the heat output of HP was $q_{h p}=1.95 \mathrm{~kW}$. In this case, the temperature of the heat carrier, $t 2$, after absorbing heat from it coming from the EWH, decreases to minus $17^{\circ} \mathrm{C}$. The temperature of the coolant at the outlet of the condenser $\mathrm{HP}(t 3)$ is plus $38^{\circ} \mathrm{C}$ (graph 3 ), and after the output from the heater $(t 4)$ decreases to plus $32^{\circ} \mathrm{C}$ (graph 1 ). Due to the gradual decrease in the temperature of the heat carrier passing through 


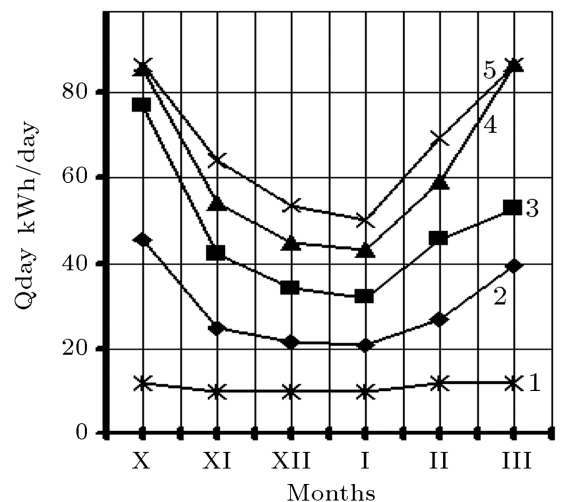

(a)

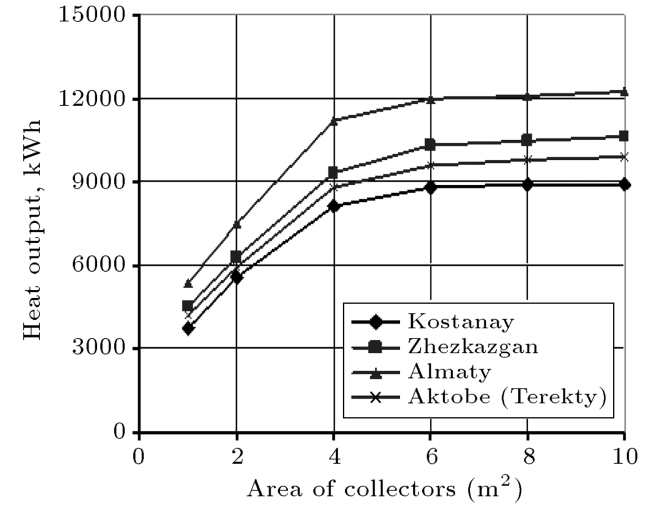

(b)

Figure 5. HP-solar collector area of solar collectors (for some climatic zones of Kazakhstan and Almaty region): (a) Dependence of average daily heat output, and (b) annual heat output.

the evaporator and the rise in the temperature of the heat carrier passing through the condenser, the thermal power of HP $\left(q_{h p}\right)$ decreases from 1.95 to 1.70 $\mathrm{kW}$ and the conversion ratio of $\mathrm{HP}\left(k_{t r}\right)$ from 2.8 to 2.4. As is known, $k_{t r}$ divides $q_{h p}$ by the power of the compressor, which is equal to $0.7 \mathrm{~kW}$. Similar patterns were observed in other capacities of SPP. For example, when RSPP $=1000 \mathrm{~W}$, temperature $t 2$ was lowered to $-16^{\circ} \mathrm{C}$, and the inlet and outlet of heating device were 46 and rose to $42^{\circ} \mathrm{C}$. HP $q_{h p}$ thermal power was $2.07 \mathrm{~kW}$ at the beginning and $1.6 \mathrm{~kW}$ at the end. Lowering the temperature of the SPP and increasing the temperature of the heating devices led to a decrease in $k_{t r}$ from 3.0 to 2.3. Calculations performed according to the above formula showed that it decreased from 3.0 to 2.3 .

When RSPP $=2000 \mathrm{~W}$, stabilization of $t 2$ is shown within $+6-+12^{\circ} \mathrm{C}$, indicating the equal power of SPP and HP. The thermal power HP $q_{h p}$ was at the beginning of $3.1 \mathrm{~kW}$, and at the end of the process 2.75 $\mathrm{kW}$. Transformation ratio of HP declined from 4.4 to 3.9 .

\section{Analysis and justification of potential IS exergy}

Table 1 shows the sources of the exergy. The base and new energyies of the system perform the same processes: hot water, heating, maintenance of microclimate, and cooling milk; conventional energy is spent for these purposes such as (electricity, gas, oil or coal), solar energy, and electric energy to drive the compressor refrigeration cars.

In the new system, consumption of traditional energy sources is significantly lower due to the realization of hidden potential or exergy. HP-solar collector subsystem has been found experimentally, in addition to the solar heat absorbed from the ambient air. HPclimate subsystem utilizes the heat accumulated in the premises of the animals from the ventilation air. HPmilk cooler subsystem utilizes the heat of the cooled milk shown in Table 1.

These types of energy were attributed to exergy, so they were potentially contained in the base system, and the new system made it possible to implement them effectively. Annual $(\Delta q)$ can be expressed in the form of annual savings from the use of traditional energy sources of new system $\left(q_{n}\right)$ from baseline $\left(q_{b}\right)$ :

$$
\Delta q=q_{b}+q_{b e e}-q_{n}-0.1 .\left(q_{b}+q_{b e e}\right),
$$

where $q_{b}$ is energy consumption in the processes of hot water, heating, microclimate in the base case; $q_{b e e}$ is electricity consumption by the driven refrigeration compressor milk-cooling unit in the base case; $q_{n}$ is electricity consumption for the HP compressor drive in the new version.

The annual economic impact of exergy can be calculated using the following formula:

$$
\begin{aligned}
\ni_{e}= & q_{b} \cdot p_{E}+q_{b e e} \cdot p_{E E}-q^{n} \cdot p_{E E} \\
& -0.1 \cdot\left(q_{b} \cdot p_{E}+q_{b e e} \cdot p_{E E}\right)
\end{aligned}
$$

where $p_{E E}$ is the price of electricity consumed by the compressor HP.

We will calculate the heat output of the HPsolar collector, depending on the area of the solar collector, with the HP compressor power equal to 1 $\mathrm{kW}$. The hourly heat output can be calculated by the formula:

$$
q_{n}=e_{s} \cdot \beta \cdot S_{S C}+2 \cdot k \cdot S_{S C} \cdot\left(t_{a i r}-t_{S C}\right),
$$

where $e_{s} \cdot \beta \cdot S_{S C}$ is the direct solar radiation absorbed by the solar collectors; $2 . k . S_{S C} \cdot\left(t_{a i r}-t_{S C}\right)$ is the warm air absorbed by surface solar collectors; $e_{s}$ is the intensity of solar radiation, $\mathrm{kW} / \mathrm{m}^{2} ; \beta$ is coefficient 
Table 1. The structure of the energy base and new options.

\begin{tabular}{|c|c|c|c|}
\hline \multirow[b]{2}{*}{ Processes } & \multicolumn{2}{|c|}{ Energy sources } & \multirow[b]{2}{*}{$\begin{array}{c}\text { Exergy when } \\
\text { using the } \\
\text { new system }\end{array}$} \\
\hline & Base system & The new system & \\
\hline Hot water, heating & $\begin{array}{l}\text { Traditional sources, } \\
\text { solar energy }\end{array}$ & $\begin{array}{l}\text { Traditional sources, } \\
\text { solar energy, heat air }\end{array}$ & Warm air \\
\hline Maintaining a climate & $\begin{array}{l}\text { Traditional sources, } \\
\text { solar energy }\end{array}$ & $\begin{array}{l}\text { Traditional sources, } \\
\text { solar energy, heat animals }\end{array}$ & Heat animals \\
\hline $\begin{array}{l}\text { Cooling perishable } \\
\text { goods }\end{array}$ & $\begin{array}{l}\text { Electrical power (for } \\
\text { driving the chiller } \\
\text { compressor) }\end{array}$ & $\begin{array}{l}\text { Electrical energy (to drive the } \\
\text { heat pump compressor) }\end{array}$ & Heat milk \\
\hline
\end{tabular}

of absorption of direct solar radiation; $S_{S C}$ is the active surface area of solar collectors; $k$ is coefficient of heat transfer between surface of solar collectors and air; $t_{a i r}-t_{S C}$ is the difference between the air temperature and solar collectors surface.

The intensities of solar radiation $\left(e_{s}\right)$ and air temperature $\left(t_{\text {air }}\right)$ are accepted by the reference climatic data.

The values of the surface temperature of solar collectors, taken as equal to the temperature of coolant circulating therein, are established experimentally (Figure 4).

The calculation results of the average daily calorific terms of Almaty region are shown in Figure 5(a). The settlement is taken as heating months, 6 months, October to March, with an average daily operation of 8 hours. The bottom graph (Figure 5(a), curve 1) shows the power consumption of the driven CHP compressor. Upper heating capacity in different areas $(S C)$ is: $S_{S C}=1,2,4$, and $10 \mathrm{~m}^{2}$.

As seen, during the heating period, the system is effective. The useful energy generated exceeds the energy spent on the HP compressor drive. The regularities are parabolic in nature, where the minimum heat output falls in the period December-January. In October and March, the highest heat output, i.e. A., increases air temperature and intensity of solar radiation. Increasing coolant temperature solar collectors leads to the growth of $k_{t r} \mathrm{HP}$.

On the basis of the data calculated, the annual heat output HP, solar collector, depending on the area of solar collectors, is shown in Figure 5(b).

Heat HP increases with the area of solar collectors, with an increase in operating costs in proportion. The optimal area of solar collector with respect HP with the capacity of a compressor is equal to 2 .
The optimum can be taken equal to the area of $4 \mathrm{~m}^{2}$ as well as a further increase; as can be seen from the graphs, heat output increases.

Estimated annual volume is produced by HP, solar collector energy in the area of $4 \mathrm{~m}^{2}$, while the condition of Almaty region is about $11000 \mathrm{kWh}$. With the cost of electricity in Kazakhstan as $p_{E E}=$ $\$ 0,045 / \mathrm{kWh}$, the annual savings from the application will be $\$ 495$. Electricity consumption during the heating season will be $2500 \mathrm{kWh}$, amounting to $\$ 112.5$.

The figures in Figure 6 show the structures of the produced heat energy in the heating months, expressed in percentages. As can be seen, the heat output of the HP-solar collector consists of four components: absorbed direct solar energy, heat of atmospheric air, heat generated during operation of the compressor and the amount of heat output. In Figure 6, graphical representation shows the distribution of components in the heating months. From the analysis, it follows that the ratio of the share of energy depends on the area of solar collectors and changes in air temperature. In the solar energy and warm air, $(Q$ se $+Q$ wa $)$ accounts for the major share. Their share throughout the entire heating period is above $50 \%$, which confirms the overall energy efficiency of the system and exergy, with an area of $4 \mathrm{~m}^{2}$, the highest proportion than in other areas.

When comparing "CHP-solar collector" heat generators with gas, coal, and oil fuels, the technological costs of energy to produce $1 \mathrm{kWh}$ of thermal energy can be calculated by the formula:

$$
m_{m}=\frac{860}{\eta_{i} \cdot Q_{m}^{\mathcal{H}}},
$$

where $\eta_{i}$ is efficiency of $i$ th heat generator; $Q_{m}^{\mathcal{H}}$ is the specific heat (kcal) released by the combustion of a unit 

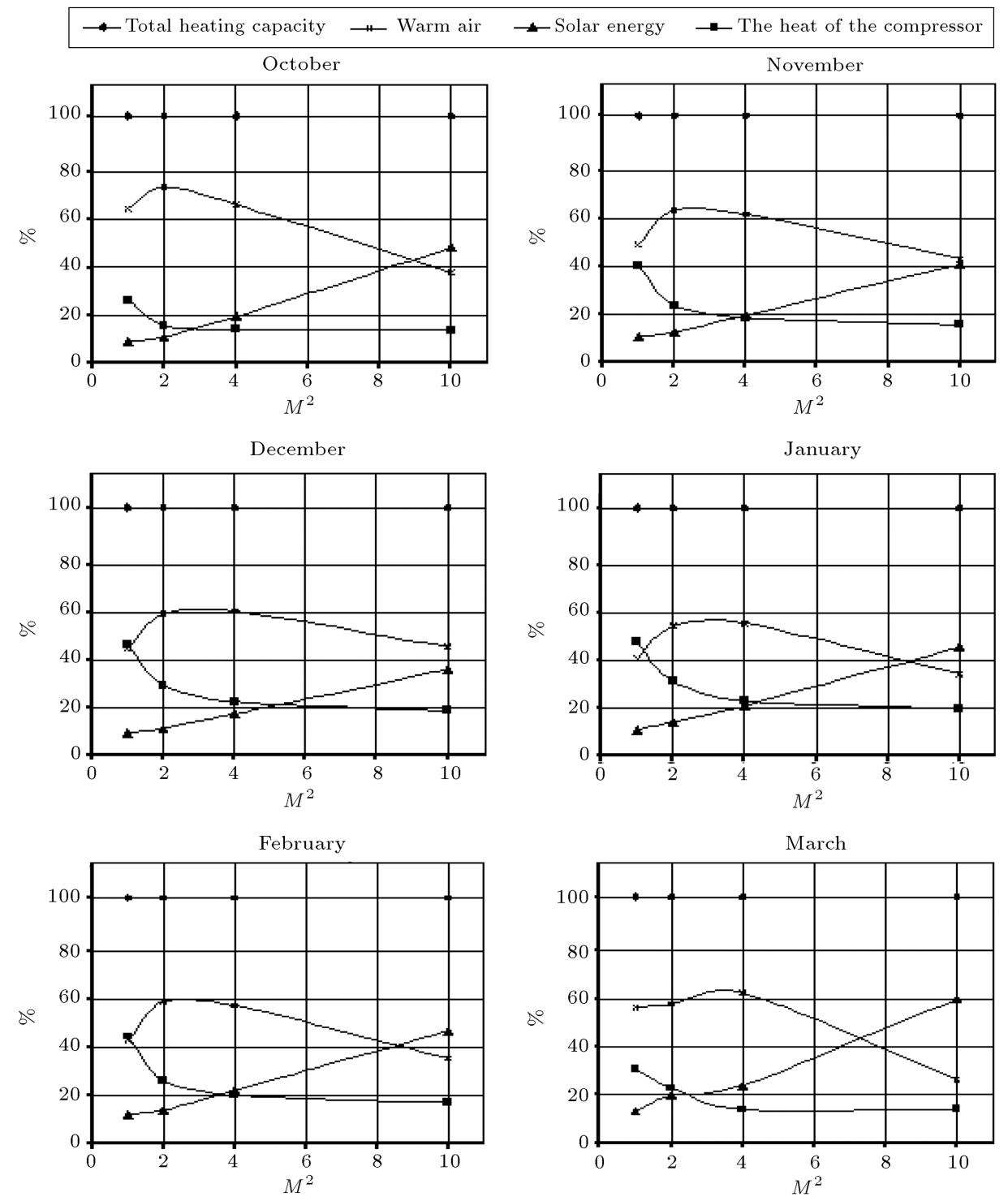

Figure 6. Dependences of average daily heat output (a) and annual heating capacity (b) HP-solar collector (for some climatic zones of Kazakhstan, and also Almaty region).

volume of the $i$ th energy carrier. In addition, the gas is measured in $\mathrm{m}^{3}$ UHL in liquid fuel in $\mathrm{kg}$.

The cost of $1 \mathrm{kWh}$ of energy produced by burning the corresponding $i$ th energy carrier $(r E i)$ is calculated at the market price of $i$ th energy carrier $\left(p_{m i}\right)$ as follows:

$$
p_{E i}=m_{m i} \cdot p_{m i} .
$$

When calculating the thermal performance of the subsystem, "CHP-climate" is necessary to determine the possibility of CHP when the compressor power is 1 $\mathrm{kWh}$. The calculated air temperature in the room is in the range of $+5-25^{\circ} \mathrm{C}$. For this temperature range, we will adopt the value of the conversion coefficient of HP equal to $k_{t r}=3$. Then, the heating capacity is $3 \mathrm{kWh}$ and cooling capacity is about $2 \mathrm{kWh}$. With an average heat generation, a cow about $0.7 \mathrm{kWh}$ is partially scattering up to $50 \%$ of the heat into the environment. CHP cooling capacity is sufficient to maintain climate conditions for 6 cows. The annual production of energy, with an average daily maintenance of animals in the room of 15 hours will be $14000 \mathrm{kWh}$. The estimated annual income from the generated energy will be $630 / \mathrm{kW}$. The results of calculations of annual energy savings for subsystem "CHP-milk cooler" are shown in Table 2.

The amount of saved energy is determined by the volume of hot water and the appropriate amount of thermal energy produced. As can be seen, with an average ratio of CHP conversion, $k_{t r}=3 \ldots 4$, for 2 hours (processing time), can cool up to 200 liters of milk from +30 to $+5^{\circ} \mathrm{C}$. Saving electricity is $10 \mathrm{kWh}$. When milking three times is a daily saving of $30 \mathrm{kWh} /$ day, annual savings are $10,800 \mathrm{kWh}$. With the cost of 
Table 2. Results calculations saving on cooling milk using CHP.

\begin{tabular}{lc}
\hline \multicolumn{1}{c}{ Index } & The value of the indicator \\
\hline Compressor type & Spiral \\
CHP compressor power, $\mathrm{kW}$ & 1.0 \\
Conversion factor CHP, $k_{t r}$ & 3.0 to 4.0 \\
The volume of the cooled milk, 1 & 200 \\
Cooling the milk temperature, ${ }^{\circ} \mathrm{C}$ & 5 to 30 \\
The volume of heated water, 1 & 250 \\
The hot water temperature, ${ }^{\circ} \mathrm{C}$ & 14 to 40 \\
The amount of produced thermal energy, $\mathrm{kWh}$ & 10 \\
The thermal energy produced per day with 3 meals a day milking, $\mathrm{kWh}$ & 30 \\
Annual energy savings, $\mathrm{kWh}$ & 10800 \\
Annual savings subsystem "CHP-milk cooler", $\$$ & 495 \\
\hline
\end{tabular}

electricity in Kazakhstan as $P_{E E}=\$ 0,045 / \mathrm{kWh}$, the annual savings from the use of CHP will be $\$ 495$.

\section{Conclusion}

The introduction of unique technologies corrosponding to the developing Solar Energy (SE), actual energy, faces economic and environmental problems. It is proposed to develop a new energy-saving technology, i.e. the use of integrated SE, which can be efficiently implemented in agro cattle farm. The main components of the system are: Solar Power Plant (SPP), milk cooler, climate unit, Heat Pump (HP), the battery heat, automatic control system and device heating and hot water consumers. The new system functions are: absorption SE, milk cooling, air-conditioning facilities, waste heat milk of animals, their accumulation and the total supply of heat to the consumer for heating and hot water. Constructive-technological scheme of an integrated system of heat supply cattle farm was founded and developed. The novelty is that it introduces an additional function: cooling and storage of perishable products, maintaining a controlled indoor environment with simultaneous utilization of excessive heat. The operation of the solar thermal system is in conjunction with a heat pump in the compressor power HP $0,7 \mathrm{~kW}$. In the course of the experiments, various solar powers (RSPP) are set from 500 to 4000 $\mathrm{W}$. The measurements showed that the temperature of the coolant in the SPP, according to the RSPP $170^{\circ} \mathrm{C}$, changes from minus to plus $250^{\circ} \mathrm{C}$, the temperature in the heating devices is increased from 49 to $650^{\circ} \mathrm{C}$, thermal power HP varies from 1.8 to $4.0 \mathrm{~kW}$, and the conversion coefficient HP $k_{t r}$ varies from 2.6 to 5.5 .

\section{References}

1. Hamakawa, Y., Recent Advances in Solar Photovoltaic Activities in Japan and New Energy Strategy Towards 21st Sentury. Proc. 16th EU PVSEC. Glasgow, pp. 2747-2752 (2000).

2. Key world Energy Statistics. International-EnergyAgency. The IEA statistics site can be accessed at: www.iea.org/statistics/.

3. Hawlader, M.N.A., Chou, S.K. and Ullah, M.Z. "The performance of a solar assisted heat pump water heating system", Applied Thermal Engineering, 21, pp. 1049-1065 (2001).

4. Lu, A., Charters, W.W.S. and Chaichana, C. "Solar heat pump systems for domestic hot water", Solar Energy, 73, pp. 169-175 (2002).

5. Chyng, J.P. "Performance analysis of a solar-assisted heat pump water heater", Solar Energy, 74, pp. 33-44 (2003).

6. Huang, B.J. and Lee, C.P. "Long-term performance of solar-assisted heat pump water heater", Renewable Energy, 29, pp. 633-639 (2003).

7. Hawlader, M.N.A. and Zakaria, M.A. Solar evaporator-collectors: analyses and applications Arthur V. Killian (Ed.), Solar collectors: energy conservation, design and applications, ch-6Nova Publication, pp. 153-190 (2009).

8. Hawlader, M.N.A. and Jahangeer, K.A. "Solar heat pump drying and water heating in the tropics", Solar Energy, 8, pp. 492-499 (2006).

9. Daghigh, R., Ruslan, M.H., Sulaiman, M.Y. and Sopian, K. "Review of solar assisted heat pump drying systems for agricultural and marine products", Renewable \& Sustainable Energy Reviews, 9, pp. 2564-2579 (2010).

10. Alalaimi, M., Lorente, S., Anderson, R. and Bejan, A. "Effect of size on ground-coupled heat pump performance", International Journal of Heat and Mass Transfer, 64, pp. 115-121 (2013).

11. Ahmad, M.W., Eftekhari, M., Steffen, T. and Danjuma, A.M. "Investigating the performance of a combined solar system with heat pump for houses", Energy and Buildings, 63, pp. 138-146 (2013). 
12. Emine, C.L. and Berrin, E. "Investigation of the effect of rollbond evaporator design on the performance of direct expansion heat pump experimentally", Energy Conversion and Management, 72, pp. 163-170 (2013).

13. Rad, F.M., Fung, A.S. and Leong, W.H. "Feasibility of combined solar thermal and ground source heat pump systems in cold climate", Energy and Buildings, 6, pp. 224-232 (2013).

14. Patent 2382281 Russian Federation IPC F24D 3/18. The system of independent heating and cooling of buildings/publ. 20.02.10.

15. Wonseok, K., Jongmin, C. and Honghyun, C. "Performance analysis of hybrid solar-geothermal $\mathrm{CO}_{2}$ heat pump system for residential heating", Renewable Energy, pp. 596-604 (2013).

16. Huang, B.J and Chyng, J.P. "Performance characteristics of integral type solar assisted heat pump", Solar Energy, 71, pp. 403-414 (2001).

17. http://www.energopolis.dp.ua.

18. Renato, M. "Dual source heat pump systems: Operation and performance", Energy and Buildings, 52, pp. $77-85$ (2012).

19. Innovation patent of Republic of Kazakhstan 28944, IPC F24D 3/08. The device for the integrated use of renewable energy/Omarov RA, Raiymbekov AE, AE Baybolov Omar DR; applicant and patentee KazNIIMESKH; publ. 09.15.2014, Bull. No. 9-3 S.

20. Omarov, R.A., Baybolov, A.E., Raiymbekov, A.E. and Omar, D.R. "Multi-zone heating and cooling system of the cattle farm on the basis of the heat pump printed", Proceedings of the 9th International Scientific Conference Energy Supply and Energy Efficiency in Agriculture, Moscow, Russia, pp. 106-116 (2014).

\section{Biographies}

Rashit Omarov is a Professor, Doctor of Engineering, and Deputy Director General for Research, in Kazakh Scientific Research Institute of Mechanization and Electrification of Agriculture, Almaty, Republic of Kazakhstan. His research interests are solar heating systems, mathematical methods heat pumps. In recent years, he has worked on combined solar systems.

Slushash Abdyagaliyeva is a Master of Science student with a degree in Land Management, senior lecturer of the Department of Geography, Planning and Cadaster, Al- Farabi Kazakh National University, geography and environmental sciences faculty, Almaty, Republic of Kazakhstan. Her research interest is land cadaster. In recent years, she has been working on studies of land management and cadaster.

Dauren Omar is a Master student majoring in Engineering, senior researcher of the Kazakh Research Institute of Mechanization and Electrification of Agriculture, Almaty, Republic of Kazakhstan. His research interests are solar heating systems, and mathematical methods of heat pumps. In recent years, he has worked in the field of information technology and renewable energy.

Murat Kunelbayev is a Master student of Physics, Senior Lecturer, at the Department of Physics, Kazakh State Women's Teacher Training University, Almaty, Republic of Kazakhstan. His research interests are solar heating systems and mathematical methods in hybrid solar systems. In recent years, he has worked on mathematical research solar collectors and micro hydro power station. 